\title{
Liberalism or Technological Modernization
}

\author{
Andrei Blinov \\ Financial University under the Government of the Russian Federation \\ Moscow, Russia \\ E-mail: aoblinov@mail.ru
}

\begin{abstract}
Under scrutiny is the problem of the Russian economy's innovation and technological potential and its potential effect on global economic crisis. This work exposes the source of the Russian economy's demoralization and economic collapse, asserting that Russia's present situation is impeding the development of its innovation-based economy as by the year 2020 to the year 2050 .
\end{abstract}

Keywords-industry; morality; Russia; crisis; safety; innovations; modernization; programs

\section{INTRODUCTION}

Today, the transfer of Russia's economy into the innovative development becomes an urgent step.

In spite of unfavorable statistics at hand, our remaining research and production potential allows for fulfillment of the innovation-driven development strategy, as the President stated it. Still, this challenging task is calling for a complex and across-the-board achievement, addressing all functional management levels. Russia's economic innovative and technological potential needs to be assessed, the indicators of and approaches to diagnosing Russian production sector's real capacity must be defined, not claiming their infallibility or the lack of alternative. It is important to determine the key technological indicators for Russia in the context of the mature economies of the world.

It is reasonable to undertake the analysis of Russia's economic development starting from general issues, onto which more private and specialized aspects would be strung. For this purpose, it is first and foremost advisable to sum up Russia's production sector macro economically. Production sector of any economy has always been and remains the backbone of national security.

Severe recession of the 90 s of the last century had witnessed deindustrialization, not so much expressed in the contracted share of the industrial sector as in the growing deterioration of industrial enterprises' physical capital and its functional depreciation, in high share of low-tech production, the lack of innovations, and the reduction in human capital assets.

The production sector's sustainable development is, from the perspective of stability, the strategic task for Russia's economy today. As many researchers outline, sustainable development of an economy is capable of boosting marketability of a country and ensuring its national security. We should talk specifically about Russia's reindustrialization, bearing in mind new industrial policy, targeted to increase labor productivity and reduce cost by the means of continuous technological upgrading. Such policy can be identified as predictive control strategy. From the perspective of the country's economic strength, it is vital to ensure that State control over strategic natural resources, energy and finance resources, the availability of which guarantees the country's independence and provides leadership in critical sustainable economic development technologies. The way out from the current state of affairs lies in the urgent audit of our potential. Application of the following principles will be instrumental on this count.

The first principle is comparative, as it is crucial today to match the development of the national economy to the outer world. The second principle is precluding, it concerns the quantity and quality assessment of a substantial development gap between Russia and leading economies in terms of "much/little". The simple statement of excursion in different process characteristics is not enough. The third principle is temporal and pertains to the temporal terms, which the existing development gap between Russia and leading countries should be translated into. In other words, it is essential to record any technological gap, evaluate it and at the least approximate the time limit within which the Russian Federation can overcome its gap with other developed economies. The fourth principle is complex. The bottom line here is to collate the analysis of technological and institutional components of Russia's economic development and of leading countries' economics. Specifically, any leading country is striking the perfect balance in two directions: technological and institutional. The high-potent institutional environment fosters usually the technological innovations, while the high-tech economy calls for progressive institutional changes. It is instrumental to understand this bond of two national economy components to detect the problem issues of development process and to determine the key directions of the country's primary efforts.

\section{PRoduction FACILITIES' DeVElopment AND GROWTH}

The "economic development" idea stands for the qualitative restructuring of a production facility that is treated as an economic system. Specifically, there is a certain discrepancy - on one hand, there is the system's qualitative structural sophistication attributed to the new development level transfer. Yet, on the other hand, a very 
new qualitative leap forward is feasible through application of mechanisms for collaboration, immanent for this system. The economic system's future state is assumed to be of greater value than its current state.

The economic "growth", understood as a change in the economic system's quantitative characteristics, is substantially narrower than the "development". However, in reality, management practice, as concerns long-term prospects in terms of strategic management, are immediately interconnected. The growth can be sustainable for a long period of time only providing the economic system's development at large. Therefore, a sustainable development is contingent upon building-up the economic system's resources and capabilities, specifically, upon the emphasis on its quantitative indicators.

Any industrial enterprise's development in the long-term may be stable, if its growth rate exceeds the market development rate, its structure constantly adapts to external environment, and its management actively controls processes taking place in the external environment. According to Joseph Schumpeter, under capitalism, the focus is usually on the tools of managing existing structures, whereas genuinely the problem exists with the mechanism of their structuring and destruction [9].

Many years of experience show that only some of the companies are capable of finding strength and time to "saddle" existing creative destruction processes, acting with the same speed and capacity essential to survive the competitive battle. Nevertheless, in the longer term this is an indispensable condition of compliance with market efficiency requirements.

In such situations, the role of the State in the economic transformation management system is instrumental. Markets can be free only if it turns mature and faultless. History shows that markets in all mature economies were developing with the direct support of the State. They formed in line with national interests under economic development strategy. We have to establish such a development-oriented type of market system that guarantees sustained economic growth under Russian conditions.

Consequently, the country's government has to direct development of markets and focus its policy on the quality of growth, or, in other words, on the growth balanced and swift, whereby the country has to strengthen its national positions on world markets, and on fair growth, when the win is received by all social groups.

The transition strategy together with the reforms are likely to encourage economic growth, whilst the development strategy should seize these opportunities to raise the living standards of the people of the nation. High standards of living based on stable industrial growth constitute the development targets for today. The effectiveness of economic strategy, therefore, is measured by enterprises' competitive performance and living standards.

Generalizing the existing ideas on economic development problems of transition economies, we support those believing that the overriding priority when building effective markets is in resolution of conflict between interests that undermines achievement of sustainability. In other words, a sustained economic progress is feasible if economic development serves the interests of the majority, rather than of vested interests of a few individuals of limited scope.

Reaching of a consensus, namely social harmony, on the development goals and trends constitutes the underlying premise for setting and implementation of the long-term economic development strategy. However, the national consensus and economic progress begin from the national elite's concordance, from overriding of its disunity.

Most crises arise not from the lack of knowledge on how to avoid or prevent them. The cause of them is the inability to resolve the conflict of interests before it triggers the crisis. Thus, the conflict resolution presents the key to the crisis control and its overcoming.

In the course of Russia's transformative development, we have been witnessing quite rapid and specific changes in industrial enterprises' external and internal environment. Accordingly, such enterprises' management should become innovative and flexible.

As we study the issue of national security, or rather of the survivability of enterprises' development in the longer run, the terms and tools of their continuous, namely, constant development, become the object of our analytic investigation.

If compare an enterprise with a life form, its main mission and motivation are longevity and development of self-potential. Potential of an enterprise usually implies a set of internal and external resources (tangible and immaterial) that can be used for achievement of outlined objectives. An enterprise will need to reinvest incessantly into development of its long-range capacity, thus, boosting its financial, marketing, technological, human, and organization assets.

\section{Sustained DEVElopMent Policy AND THE Role OF THE STATE IN TRANSITION ECONOMY}

Continued development of an enterprise implies its management system can prevent crises that threaten strategic potential of its future development. Long-lived companies, according to Arie De Geus, have the innate capacity to use emerging crises to their advantage, in a timely fashion recognizing them as new opportunities and alternative ways for company growth [9]. Indeed the strategy of an industrial enterprise is to develop its anticrisis management capacity. The ability of an enterprise to learn faster and better than its rivals becomes its most sustainable competitive advantage.

The strategic management system of an enterprise ought to incorporate the crisis prevention and overcome tools. The multi-decade experience of enterprise development in different countries testifies that crises are inevitable; they arise repeatedly throughout an enterprise's life span and, largely, determine the life of the enterprise. Even the 
"natural death" of a company may appear as the effect of yet another and final crisis in its life.

Understandably, crises are not the only and best model of learning. They unexpectedly cause issues and put enterprises against radically new challenges. The failure to resolve new problems can trigger a serious breakdown; the response must be immediate, but conventional systems and procedures do not guarantee adequate speed of decisionmaking, leaving little time to do so. Considered options are limited to those that require a relatively short period of time to implement them. Commonly taken tough decisions decrease an enterprise's strategic potential. The heavier the enterprise's capacity is limited, the deeper it drifts into crisis.

Conditions necessary for emergence of a crisis involve rapid and unexpected changes inside an organization or in its external environment. Unavailability of required resources for an adequate response to these changes forms the second-order conditions. Eventually, the developments get out of hand and become uncontrollable.

Crisis' key function is the elimination of less stable and viable components, which to the utmost cripple the organized nature of the entire system. Consequently, the system streamlines its complexity and improves orderliness; otherwise, the economic system collapses.

When mechanisms of economic health, as part of the anti-crisis management, work as a well-oiled machine, enterprises transform without loss of their potential for future development. The cycles of an enterprise stationary state and transformation are rotating with time, and this process, according to Henry Mintzberg, may bear various forms: periodical shakeouts, "back-and-forth" shifts, lifecycles or a regular adaptation process. Such development is always based on the process of timely and relevant building of an enterprise's strategic capacity [5].

The strategic potential development in the economic system composes the foundation of the national security.

Whilst analyzing the economic security of an enterprise, the evaluation of one process or another should be carried out beyond simple referencing to accepted standards, which are more often than not arbitrary due to the insufficiency of conducted research. The economic security indicators should include assessment of the enterprise performance and its system status, as compared to the average market level, and its dynamics. In case of the industry-specific indices excess, we may talk about the sustainable competitive advantages, assumption validity, adequacy of resources, and the strategic flexibility. Further, each economic security index can be chartered with the positions describing the probability and depth of enterprises' strategic potential destruction.

\section{SPECIFICS OF INDUSTRIAL ENTERPRISES} MANAGEMENT UNDER STRATEGIC UNEXPECTEDNESS

There are no excuses for a rapid destruction of the country's economic strength. Since the destruction of the strength makes the emergence of next crises inevitable. This is immoral towards those living today and future generations [8].

The objective of the anti-crisis management is to neutralize the most perilous phenomena in external and internal environment of an enterprise. Identification of most danger zones requires the availability of an early-warning system. Complexity and speed of decision-making should be up to the complexity and rate of change in the external and internal environment.

Management in the conditions of strategic unexpectedness proceeds from decisions that must be taken upon emergence of weak signals, meaning early and general factors of upcoming landmark events [1]. In other words, the strategic management should be proactive. However, that means that the external environment monitoring and its analysis have to be responsive to weak warning signals. Instead of waiting for completeness of information, the enterprise has to decide which measures to launch under different-level situations, entailing hazards and or opportunities.

Scenarios of possible developments supply tools helping capture and study latent weak signals. These scenarios serve as the "signal-to-noise" filter. Depicted events are perceived with less noise background, with more expressive profile, and distinct contours.

Identification of weak signals demands the enterprise management's competence to find adequate to the situation methods of observation and analysis, broad experience, high sensitiveness, analysis selectivity, and ultra-high qualification. In fact, the management by reference to weak signals is always used in combination with traditional management scenarios by reference to strong signals based on regular planning. The problem is that in Russia this approach has been known and applied less than other schemes, while the need in its application increases dramatically.

This influence is diverse but hardly always obvious and, therefore, has been underestimated. Crimes in the world of bankruptcy dramatically hinder restoring health of enterprises under crisis. They inevitably lead to the destruction of enterprises' economic strength, contributing to rise and the exacerbation of economic crisis in the industry, region, and country.

The legitimization of criminal money and corruption are thwarting formation of effective market institutions and disrupting the already going institutions. They expedite formation of deformed markets driven by interests of some of its participants, split demand and supply, and "inflate" financial bubbles. These crimes, if they are widespread, make economic growth impossible. The efficiency of fighting economic crimes affects the social standard of living and the business activity rate of the population. 


\section{ECONOMIC CRIME'S EFFECT ON DYNAMIC DEVELOPMENT OF INDUSTRIAL ENTERPRISES}

In the ' 90 s, our country lost such a serious portion of its strategic potential as she had not lost for many centuries. The country's national security decreased drastically. The crisis of the '90s saw the destruction of the economic system's morality and the loss of moral compass, instead of moral renovation. Such development cannot be sustained in principle.

We have to boost dramatically the competitive advantages of Russia's economy in the area of development and the use of new technologies. In the West, the modern economic paradigm, regardless of its apparent faults, produces competitive goods and services, while we do not. Russia has not yet worked up on her section of the way.

I am convinced that the present climate of opinion and moral standards will not let us develop an innovative economy in Russia either by the year 2020 or by 2050 . The new strategic paradigm urges relevant standards of morality. This has always been in all times and in all countries [2].

It is of concern that the past eight good years raised a generation of politicians and top-managers accustomed to "the wealth generation management" in hothouse conditions with expanding markets and no rivalry with stronger foreign competitors, and no need for considerable investments in new technologies, when the policy is out of the public's interest. Such elites lack any crisis management experience and necessary skills and it is not ready for a constant uphill job.

Even if owners and top-managers of Russian businesses have created strong brands with a strong standing of their companies in the market, they give up struggling and sell out their business to stronger foreign rivals once the latter step up their competition, once brand new technologies and large-scale investing is required.

\section{MORAL PRINCIPLES OF NATIONAL SECURITY}

I suppose that the crisis attacks most of all immoral economies, because it is the immorality of business, authorities, and the populace that provokes crises. Everyone have been aware that this should not be done but someone did, hoping to make a pretty penny out of this, while the crisis would leave him or her cold. Today's crisis presents a new stage of economic and moral recovery for many countries. Governments of these countries should look at the future development of their economies from the moral positions with due regard to their historic, religious, and cultural traditions [2].

Russia's new economic strategy is calling for the development of knowledge-based moral economy. All discussions about the necessity to decide economic problems first and moral problems after are wrong, and in fact, are even noxious. The all-level authorities should protect new ethic by law and condition its strict observance, while the civic society will have to learn to control the regime. Struggle against economic crimes is the powerhouse of this process. Economic and moral renewal of our community largely depends on how successful this will go.

Mass media with their powerful effect on social conscience indeed are expected to serve their purpose in the development of knowledge-based and moral economy. Underestimation of mass media's role would be a serious mistake. It is necessary to persistently build up and develop new models of conduct, fine and bright, day after day, looking for these patterns in real activities of people and promoting their extensive application. The media world should develop men's self-confidence, confidence in their skills, and confidence in their capabilities. They should encourage the creativity, self-enhancement, the desire to help each other, and developing social binds and networks. They must support the confidence that altogether we can handle economic crime and corruption.

We need the moral breakthrough, which has to be prepared today; tomorrow it will be too late because we may face irreversible consequences of the society's decomposition and the loss of statehood. While this is a lengthy process.

\section{REFERENCES}

[1] Ansoff I., The New Corporate Strategy / I. Ansoff. Translation from English, SPb.: Piter.Com, 1999. - P.416.

[2] Blinov A.O., The Marketability of Managing Human Resources' Creativity at Modern Organization// Predprinimatelstvo. - 2011, No.6, PP. 23-35.

[3] Blinov A.O., The Transformational Crisis Control and Moral Novels// Ekonomist. - 2014, No.6, PP. 89-96.

[4] Blinov A.O., Rudakova O.S., Safonov E.N., The Methodological and Guidance Basis of Diagnosing Modern Organizations/. - M.: Integratsiya, 2013, - P. 259.

[5] Geus A., The Living Company: Growth Learning and Longevity in Business/. - SPb.: Stockholm School of Economics in St. Petersburg, 2004. - P. 221

[6] Kozlovsky E.A., Komarov M.A., Makrushin R.N., BRICS Countries' Opportunities for Cooperation in Fuel \& Energy // International Organizations Research Journal. - 2012. - No. 2(37), PP. 4-6.

[7] Mintzberg H., Strategic Management Schools / H. Mintzberg, B. Alstrand, J. Lampel; Translated from English, SPb., Piter, 2000. - P. 336.

[8] Rodionova I., Production and High-Tech Exports Dynamics in the $19^{\text {th }}$ Century: World and Russia // Proceedings of the International Conference: Russia in World Economy. M.: New Economic Association, February 19. - 2013. - P. 362.

[9] Russia 2013: Data Book / Rosstat. - M., 2013. - P. 68.

[10] Eskindarov M.A., Corporation as a Form of Russian Enterprises' Market Adjustment. The book: Resources Potential of Market Growth - M.: Russia's Way (Put' Rossii), 2003, PP. 16-25.

[11] Amabile T. M., Social Psychology of Creativity: A Consensual Assessment Technique // Pers. \&Soc/ Psychol. - 2003. - V. 43.

[12] Sorter G.N., An "Events" Approach to Basic Accounting Theory// The Accounting Review/-1969/ January. - Vol. 44. 